\title{
Sb-Si Alloys and Multilayers for Sodium Ion Battery Anodes
}

\author{
W. Peter Kalisvaart, ${ }^{\dagger,+*}$ Brian C. Olsen, ${ }^{\dagger, t}$ Erik J. Luber, ${ }^{\dagger, t}$ and Jillian M. Buriak ${ }^{\dagger, t, *}$ \\ $\dagger$ Department of Chemistry, University of Alberta, 11227 Saskatchewan Drive, \\ Edmonton, Alberta T6G 2G2, Canada \\ \$National Institute for Nanotechnology, National Research Council Canada, 11421 \\ Saskatchewan Drive, Edmonton, Alberta T6G 2M9, Canada
}


ABSTRACT: Silicon has a theoretical sodium-storage capacity of $954 \mathrm{mAh} / \mathrm{g}$ which even exceeds that of tin $(847 \mathrm{mAh} / \mathrm{g})$. However, this capacity has never been reached in practice. Antimony is one of the best-performing Na-storage materials both in terms of capacity and cycling stability. By combining silicon and antimony, either by cosputtering or depositing multilayers with bilayer thickness down to $2 \mathrm{~nm}$, capacities exceeding even the theoretical capacity of $\mathrm{Sb}(660 \mathrm{mAh} / \mathrm{g})$ can be achieved. Minor addition of silicon of 7 at. $\%$ or $7 \mathrm{wt} \%$ ( 25 at $\%$ ), increases the measured reversible capacity from $625 \mathrm{mAh} / \mathrm{g}$ for pure $\mathrm{Sb}$ to 663 and $680 \mathrm{mAh} / \mathrm{g}$, respectively. All Sb-rich (>50 at\%) compositions show improved cycling stability over elemental $\mathrm{Sb} . \mathrm{Si}_{0.07} \mathrm{Sb}_{0.93}$ reached a maximum capacity of $663 \mathrm{mAh} / \mathrm{g}$ after 140 cycles and showed negligible capacity degradation up to 200 cycles. The fully sodiated state in co-sputtered films evolves from single-phase amorphous to a mixture of a Sb-rich and Si-rich sodiated phases as cycling progresses, when the Si content is between 75 and 50 at.\%. The typical desodiation signature of $\mathrm{c}-\mathrm{Na}_{3} \mathrm{Sb}$ is observed only after 100 cycles or more. Careful examination of the voltage profiles of multilayers shows that they initially tend towards intermixing between the Si and Sb layers, contrary to expectations based on the phase diagram. When the Si and $\mathrm{Sb}$ layer thickness is decreased to $2 \mathrm{~nm}$, the multilayer and cosputtered film behave almost identically. A general direction for finding promising multicomponent sodium ion battery (SIB) alloy anodes is proposed.

KEYWORDS: Sodium ion batteries, silicon, antimony, multilayers, cycling 


\section{Graphical Abstract}

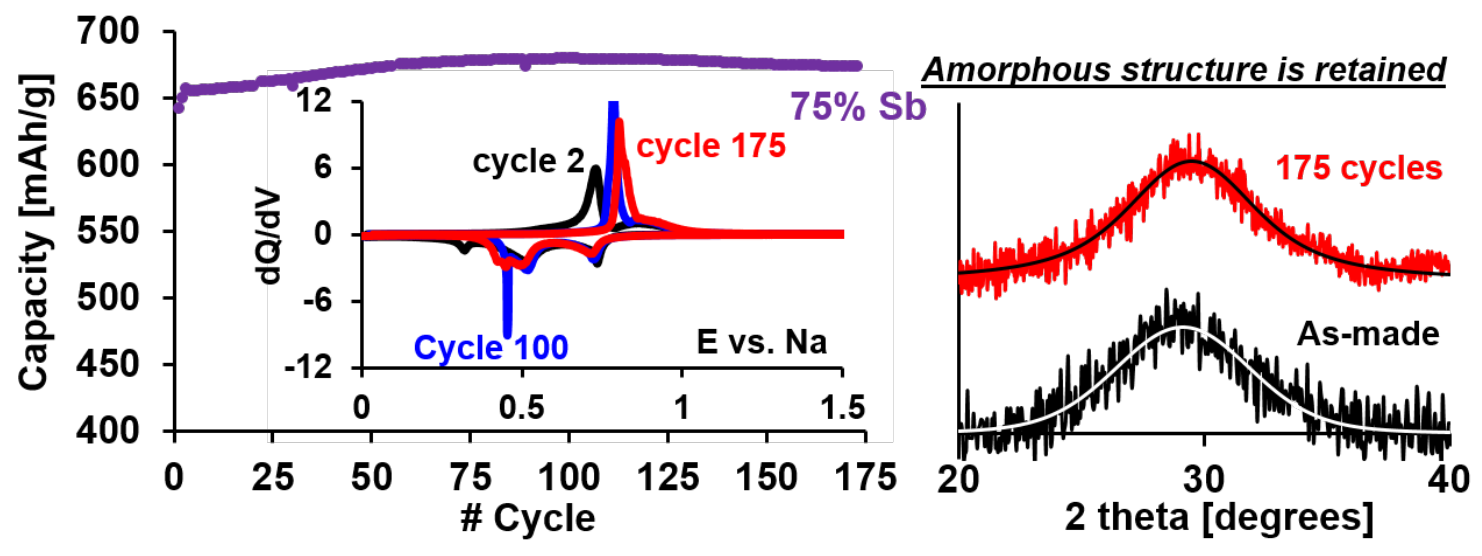




\section{INTRODUCTION}

Silicon has been intensively studied as a Li-ion battery (LIB) anode material because of its high theoretical storage capacity of $\sim 3600 \mathrm{mAh} / \mathrm{g}^{1,2}$. It also has one of the highest theoretical reversible capacities for sodium-ion battery (SIB) anodes (954 mAh/g), corresponding to a one-to-one ratio of sodium to silicon ( $\mathrm{NaSi}$ ). Because of the low density of silicon, the specific capacity even exceeds that of elements that form alloys with $\mathrm{Na}$ that have much higher stoichiometries, such as $\mathrm{Sn}\left(\mathrm{Na}_{15} \mathrm{Sn}_{4}, 847 \mathrm{mAh} / \mathrm{g}\right)$ and $\mathrm{Sb}$ $\left(\mathrm{Na}_{3} \mathrm{Sb}, 660 \mathrm{mAh} / \mathrm{g}\right)$. However, for reasons that are not entirely clear, the experimental reversible $\mathrm{Na}$ storage capacity of elemental Si has always been found to be much lower. $\mathrm{Xu}$ et al. found that electrodes with 50\% amorphous Si nanoparticles ( $\sim 20 \mathrm{~nm}$ diameter), $30 \%$ carbon additive and $20 \%$ binder have $\sim 300 \mathrm{mAh} / \mathrm{g}$ capacity, but the voltage profiles show no evidence of sharp phase transitions from $\mathrm{Si}$ to $\mathrm{NaSi}^{3}{ }^{3}$ Jangid et al. investigated sputtered Si thin films and found comparable capacities, $\sim 300 \mathrm{mAh} / \mathrm{g}$ for a $50 \mathrm{~nm}$ film, but the cycling stability was very poor with only $125 \mathrm{mAh} / \mathrm{g}$ remaining after 100 cycles. ${ }^{4}$ The highest capacity for pure Si reported so far is $\sim 600 \mathrm{mAh} / \mathrm{g}$ at a low rate of $20 \mathrm{~mA} / \mathrm{g}$ for a mesoporous material prepared by magnesiothermic reduction of a porous $\mathrm{SiO}_{2}$

scaffold. ${ }^{5}$ A theoretical study by Chou et al. found that alloying Si with $\mathrm{Na}$ is thermodynamically unfavorable up to a $\mathrm{Na} / \mathrm{Si}$ ratio of $1: 3$, but by only a few $\mathrm{kJ} / \mathrm{mol}$ of atoms, with respect to a segregated mixture of amorphous $\mathrm{Si}$ and $\mathrm{Na}$ metal. The formation energy of crystalline $\mathrm{Si}$ with one in 64 atoms substituted by $\mathrm{Na}$ was found to be $+1.90 \mathrm{eV}$ with respect to $\mathrm{Na}$ metal. ${ }^{6}$ This may explain why single-crystal $\mathrm{Si}$ can be used as a substrate when exploring novel SIB anode materials without it making a noticeable contribution to the measured capacity. ${ }^{7}$ Moreover, the activation energy for 
diffusion of $\mathrm{Na}$ in $\mathrm{Si}$ was found to be on the order of $100 \mathrm{~kJ} / \mathrm{mol}$, which is considerably higher than that of $\mathrm{Li}$ in $\mathrm{Si}(62 \mathrm{~kJ} / \mathrm{mol})$ or $\mathrm{Na}$ in $\mathrm{Sn}(53 \mathrm{~kJ} / \mathrm{mol}),{ }^{6}$ which may explain the poor rate capability. ${ }^{3}$

Elemental $\mathrm{Sb}$ has been shown to be one of the best performing anode materials for Na-ion and even K-ion batteries ${ }^{8}$. Simply ball-milling a mixture of commercial $\mathrm{Sb}$ powder, a carbon conductive additive, and binder resulted in a composite with a capacity of $\sim 575 \mathrm{mAh} / \mathrm{g}$ based on the weight of $\mathrm{Sb}$ in the electrode and virtually no capacity decay for 160 cycles. ${ }^{9}$ However, ball-milling any form of carbon will generally result in a high surface area material that may make a substantial contribution to the measured capacity, rendering determination of the Sb-specific capacity rather difficult. ${ }^{10}$ Depositing the active material as a film on a conductive substrate allows one to determine the intrinsic reversible capacity unambiguously. $100 \mathrm{~nm}$ thick Sb films show a maximum capacity of approximately $635 \mathrm{mAh} / \mathrm{g}$ when deposited onto a Si substrate. The capacity starts to rapidly degrade after $\sim 35$ cycles, which is much less than many published results on $\mathrm{Sb}$ powder electrodes. ${ }^{9-13}$ Further improvements in the cycling stability of elemental $\mathrm{Sb}$ resulting from alloying additions will therefore become obvious much more quickly in thin film studies. Indeed, a $100 \mathrm{~nm} \mathrm{Sb}_{80} \mathrm{Bi}_{10} \mathrm{Sn}_{10}$ film showed stable capacity of around $600 \mathrm{mAh} / \mathrm{g}$ for over 100 cycles under identical conditions as elemental $\mathrm{Sb}{ }^{7}$

$\mathrm{Bi}$ and $\mathrm{Sn}$ form a stable solid solution (Bi) and intermetallic compound $(\mathrm{Sn})$ with $\mathrm{Sb}^{14}$ but are also quite heavy. Si and Ge are much lighter elements, and given their relative positions on the periodic table, might be expected to behave similarly to Sn. However, neither Si nor Ge has any stable compounds with, and only minor solid solubility in, both Sn and Sb. Metastable Sn-Ge-Sb films, on the other hand, have 
capacities in excess of $800 \mathrm{mAh} / \mathrm{g}$ and a contribution from Ge corresponding to $3 \mathrm{Na} / \mathrm{Ge}$, which far exceeds the maximum reversible sodiation capacity of elemental Ge (around 1 $\mathrm{Na} / \mathrm{Ge}) .{ }^{15,16}$ Therefore, one might expect Si to contribute more than the $\sim 300 \mathrm{mAh} / \mathrm{g}$ found for elemental films and powders when it is added to another high-capacity material to form a (metastable) binary or ternary alloy.

In the present paper, we report on the electrochemical properties such as capacity, voltage profile and cycling stability as a function of composition of Si-Sb cosputtered alloy films. The as-deposited films are amorphous over the entire compositional range, but indications of phase segregation in the fully sodiated state can be inferred from the voltage profiles in advanced stages of cycling (i.e. $>100$ cycles). Multilayer films with different bilayer thicknesses are also included to further understand the influence of phase separation and microstructural length scale on the capacity, voltage profiles and cycling stability. Co-sputtered $\mathrm{Si}_{0.25} \mathrm{Sb}_{0.75}$ is found to have the largest total capacity of 680 $\mathrm{mAh} / \mathrm{g}$, which is higher than elemental $\mathrm{Sb}$. However, the capacity decreases with increasing Si content as well as increasing layer thickness in the multilayers. The multilayers undergo homogenization, as their voltage profiles become similar to the cosputtered films with cycling. Even though $\mathrm{dQ} / \mathrm{dV}$ curves point to the formation of c$\mathrm{Na}_{3} \mathrm{Sb}$ for all the materials that were investigated, the amorphous structure of the asdeposited films is preserved in the desodiated state after 175-200 cycles, except for $\mathrm{Si}_{0.07} \mathrm{Sb}_{0.93}$. Based on these results, a more general strategy for identifying alloys with improved cycling stability is proposed. 


\section{EXPERIMENTAL SECTION}

Solvents and reagents. Dichloromethane and isopropanol were purchased from Fischer Scientific. Fluoroethylene carbonate (99\%) and metallic sodium (99.9\%) were purchased from Sigma-Aldrich. Sodium perchlorate $\left(\mathrm{NaClO}_{4},>98 \%\right)$, ethylene carbonate (99\% purity) and diethyl carbonate ( $>99 \%$ ) were purchased from Alfa Aesar.

Film Deposition. $\mathrm{Si}_{\mathrm{x}} \mathrm{Sb}_{1-\mathrm{x}}$ films were co-deposited onto Si chips $\left(1 \mathrm{~cm}^{2}\right)$ or 304 stainless steel spacers. The Si wafers were boron-doped with a resistivity of $<0.005$ $\Omega \bullet \mathrm{cm}$. Substrates were cleaned by sonication in $\mathrm{CH}_{2} \mathrm{Cl}_{2}$, Milli-Q water $(18.2 \mathrm{M} \Omega \bullet \mathrm{cm})$ and isopropanol for 10 minutes each. Si and $\mathrm{Sb}$ were deposited using confocal $\mathrm{DC}$ and RF magnetron sputtering respectively on an ATC Orion 8 sputter system (AJA International Inc.). Deposition rates were adjusted as necessary based on the desired compositions. Detailed sputtering conditions are listed in Table S1. Deposition was performed in the sputter-up configuration under continuous substrate rotation to ensure lateral film height uniformity. The nominal total thickness of the films was $100 \mathrm{~nm}$. Sample weights were determined after deposition using a Mettler Toledo XP6U balance with a repeatability of $0.15 \mu \mathrm{g}$.

Electrochemical measurements. Electrochemical measurements were performed in half-cell configuration with a $\mathrm{Na}$ foil counter electrode inside a 2032 coin cell. All coin cell parts were purchased from MTI. $1 \mathrm{M} \mathrm{NaClO}_{4}$ in 1:1 ethylene carbonate:diethyl carbonate with $5 \mathrm{v} / \mathrm{v} \%$ fluoroethylene carbonate was used as the electrolyte. Cycle life testing was performed on an Arbin BT2000 battery testing system. The voltage limits were set to 0.001 and $2.5 \mathrm{~V}$ vs. $\mathrm{Na} / \mathrm{Na}+$ for co-sputtered films. For elemental $\mathrm{Sb}$ or multilayers capped with $\mathrm{Sb}$, the upper limit was decreased to $2.25 \mathrm{~V}$ as 
electrolyte oxidation was observed to start slightly below $2.5 \mathrm{~V}$ on a pure Sb surface. The current densities (measured in $\mathrm{mA} / \mathrm{g}$ ) and the specific capacities of the material (measured in $\mathrm{mAh} / \mathrm{g}$ ) were calculated using the measured sample weights.

Characterization. X-ray diffraction (XRD) analysis on as-deposited and annealed (up to $350{ }^{\circ} \mathrm{C}$ on a hotplate under inert atmosphere) films was performed on an AXS diffractometer (Discover 8, Bruker, Madison, WI) with $\mathrm{Cu}-\mathrm{K} \alpha$ radiation $(\lambda=1.5406$ $\AA$ ). The diffractometer was equipped with a Histar general-area two-dimensional detection system (GADDs) with a sample-detector distance of $22 \mathrm{~cm}$. For some measurements, a Rigaku Ultima IV multi-purpose diffractometer with $\mathrm{Cu}-\mathrm{K} \alpha$ radiation and $285 \mathrm{~mm}$ goniometer radius was used, depending on instrument availability. Phases were identified using the database of EVA software. Scanning electron microscopy (SEM) analysis was carried out with a Hitachi S-4800 field emission SEM (Hitachi, Clarksburg, MD) or a ZEISS Sigma FESEM operating at $5 \mathrm{kV}$ and $20 \mu \mathrm{A}$. Prior to characterization, the electrodes were taken out of the coin cells and rinsed with diethyl carbonate to remove residual salt, soaked in acetonitrile and dried.

\section{RESULTS AND DISCUSSION}

XRD patterns of $\mathrm{Si}_{\mathrm{x}} \mathrm{Sb}_{1-\mathrm{x}}$ co-sputtered films are shown in.Figure $\mathrm{S} 1 \mathrm{~A} 100 \mathrm{~nm}$ elemental Sb film shows sharp (003) and (104) peaks indicating good crystallinity. Only a broad hump centered between $28.9^{\circ}\left(\mathrm{Si}_{0.75} \mathrm{Sb}_{0.25}\right)$ and $29.5^{\circ}\left(\mathrm{Si}_{0.07} \mathrm{Sb}_{0.93}\right)$ is visible for the cosputtered films, although a narrowing of the peak and an increase in the signal-to-noise ratio is observed as the $\mathrm{Sb}$ content increases. These structural data are in good agreement with these previous reports in terms of XRD peak position and the amorphous nature of the films. Co-sputtered thin films of Si-Sb have been studied in the literature for their 
application in phase-change memory (PCM) devices, where it is found that as-deposited films are amorphous over almost the entire compositional space, ranging from $\mathrm{Si}_{0.04} \mathrm{Sb}_{0.96}$ to $\mathrm{Si}_{0.97} \mathrm{Sb}_{0.03}{ }^{17,18}$ The equilibrium phase diagram of $\mathrm{Si}$-Sb shows no intermetallic compounds and negligible solid solubility, ${ }^{14}$ and the Gibbs free energy of mixing is positive over the entire compositional range. ${ }^{17}$ Nevertheless, the metastable phase produced by sputtering is surprisingly stable. Even after annealing up to $350{ }^{\circ} \mathrm{C}$ for 2 hours, $\mathrm{Si}_{0.6} \mathrm{Sb}_{0.4}$ films still retain a nanocrystalline structure (see Figure $\mathrm{S} 2$ ).
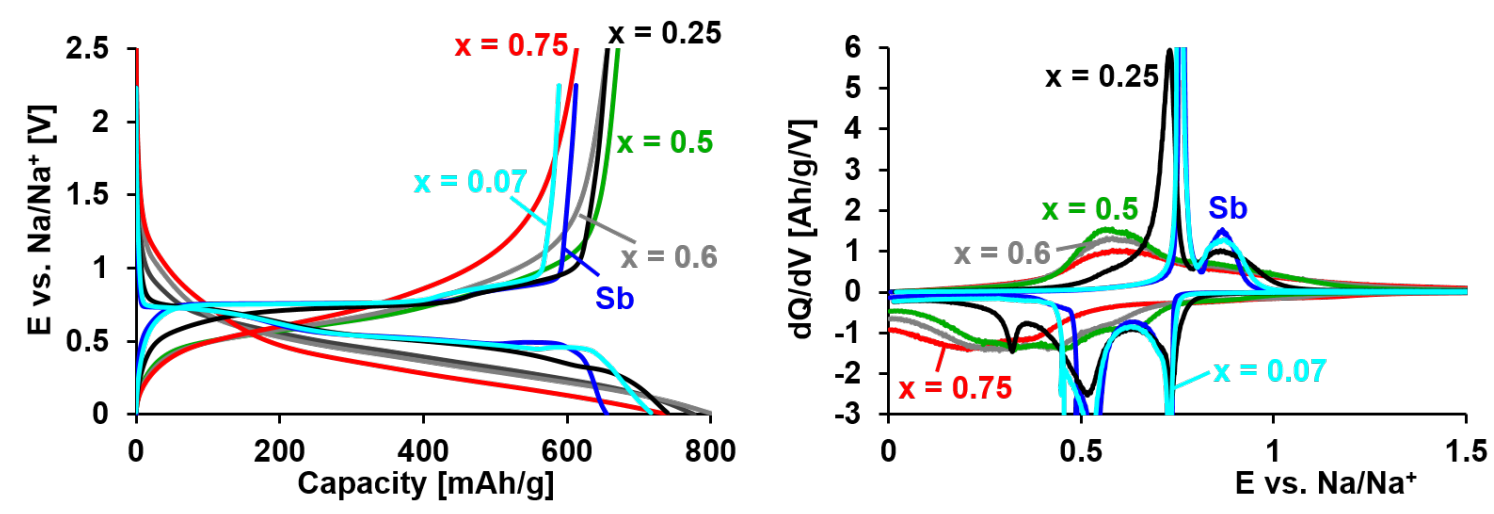

Figure 1. Voltage profiles and differential capacity curves for co-sputtered $\mathrm{Si}_{\mathrm{x}} \mathrm{Sb}_{1-\mathrm{x}}$ films in their second cycle at $100 \mathrm{~mA} / \mathrm{g}$ current density.

Figure 1 shows the constant-current voltage profiles and dQ/dV curves of the second cycle for pure $\mathrm{Sb}$ and $\mathrm{Si}-\mathrm{Sb}$ alloy films with $\mathrm{x}=0.07,0.25,0.5,0.6$ and 0.75 . With increasing Si content, the voltage plateau between $\sim 50$ and $400 \mathrm{mAh} / \mathrm{g}$ becomes ever more sloping. This is also reflected in the $\mathrm{dQ} / \mathrm{dV}$ curves as the absence of welldefined plateaus means there are no sharp peaks in the $d Q / d V$ plot either. Only the $d Q / d V$ curves for $\mathrm{x}=0.07$ and 0.25 show a shape of the sodiation curve that is very similar to elemental $\mathrm{Sb}$, a broad peak centered around $0.53 \mathrm{~V}$ flanked by two sharper features, one of which is at a lower potential compared to elemental $\mathrm{Sb}$. The sodiation potentials gradually shift to lower values when the Si content is increased further. For desodiation, 
the peak potentials coincide with elemental $\mathrm{Sb}$ for $\mathrm{x}=0.07 . \mathrm{Si}_{0.25} \mathrm{Sb}_{0.75}$ shows a broader peak at slightly lower potential. Beyond $\mathrm{x}=0.25$, the desodiation peaks are very broad and no longer resemble bulk Sb at all.

From the shape of the voltage profiles and $\mathrm{dQ} / \mathrm{dV}$ curves, several inferences about material behavior in the initial cycles can be made. The absence of a sharp plateau for $\mathrm{x}>0.25$ indicates that crystalline $\mathrm{Na}_{3} \mathrm{Sb}$ is not formed. The fully sodiated state may be a ternary $\mathrm{Na}-\mathrm{Si}$-Sb phase or a very finely dispersed mixture of $\mathrm{Na}_{3} \mathrm{Sb}$ and $\mathrm{Na}_{\mathrm{x}} \mathrm{Si}$ where $\mathrm{Na}_{3} \mathrm{Sb}$ domains are too small for a crystalline phase to form. Colloidal Sb particles with narrow size distribution around $10 \mathrm{~nm}$ were observed to have broad $\mathrm{dQ} / \mathrm{dV}$ features appearing next to the peaks characteristic for bulk Sb. ${ }^{11}$ It is likely, therefore, that a further decrease of the size of the Sb domains leads to even more broadening, eventually eliminating any bulk-like features altogether.

Flat voltage plateaus are usually associated with distinct phase transitions where a new phase with greatly increased sodium concentration, and hence also much larger volume, is nucleated. Such an abrupt volume change leads to material pulverization and negatively affects the cycling stability, although this is also highly dependent on the mechanical properties of the material. ${ }^{19}$ The absence of clear plateaus for $\mathrm{x}=0.50,0.60$ and 0.75 and their much decreased width for $\mathrm{x}=0.25$ compared to elemental $\mathrm{Sb}$, might therefore strongly influence the cycling stability. 


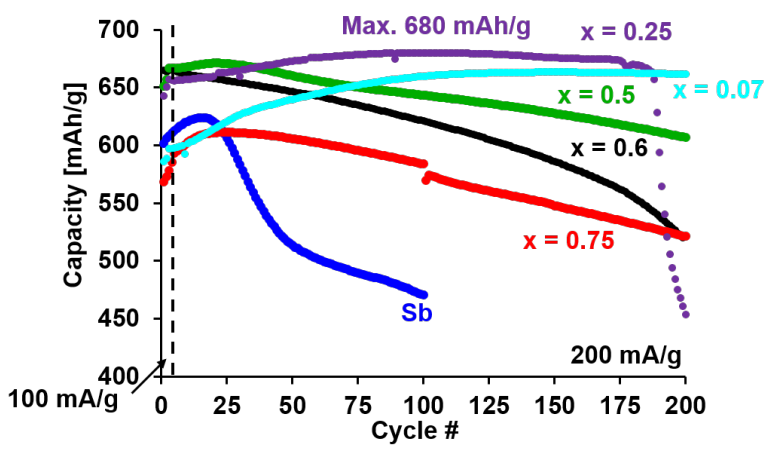

Figure 2. Reversible (=desodiation) capacity vs. cycle number for elemental Sb and cosputtered films with different compositions. $\mathrm{Sb}, \mathrm{x}=0.60$ and $\mathrm{x}=0.25$ are on steel substrates, $x=0.75, x=0.50$ and $x=0.07$ are on Si substrates. There is a 5-day break in the data for $\mathrm{x}=0.75$ on $\mathrm{Si}$ at cycle 100 . Available cycling data on different substrates are included in Figure S6.

The capacity as a function of cycle number for $100 \mathrm{~nm}$ thick $\mathrm{Sb}$ and co-sputtered $\mathrm{Si}_{\mathrm{x}} \mathrm{Sb}_{1-\mathrm{x}}$ films is shown in Figure 2. The coulombic efficiencies are plotted in Figure $\mathrm{S} 3$ and are consistently between 90 and 95\%. A summary of the maximum capacity and capacity retention after 200 cycles as a function of composition in both atomic and weight percent is shown in Table 1 . Sb should be able to store $660 \mathrm{mAh} / \mathrm{g}$ but the measured reversible capacity never exceeds $625 \mathrm{mAh} / \mathrm{g}$, which is reached after $\sim 15$ cycles and degrades rather rapidly after that, consistent with previous studies. ${ }^{7}$ On the other hand, Sb-rich co-sputtered materials have superior cycling stability to elemental Sb, as predicted from the shape of the voltage profiles. Although $\mathrm{Si}_{0.07} \mathrm{Sb}_{0.93}$ starts off at lower capacity than elemental Sb, 585 vs. $602 \mathrm{mAh} / \mathrm{g}$, the maximum capacity reaches 663 $\mathrm{mAh} / \mathrm{g}$ around cycle 150 and shows virtually zero degradation up to cycle 200 . The capacity of $\mathrm{Si}_{0.25} \mathrm{Sb}_{0.75}$ increases from $651 \mathrm{mAh} / \mathrm{g}$ in the first cycle to a maximum of 680 $\mathrm{mAh} / \mathrm{g}$ in the 100th cycle which is the highest measured capacity for all the investigated compositions. The material shows only minimal degradation between cycle 100 and 175 , but the capacity suddenly drops after that point. After the coin cell was opened, part of 
the electrode was seen to have dried up and the active material showed severe delamination in the same area as shown in Figure S4. For higher Si-contents, the capacity degradation increases although $\mathrm{Si}_{0.5} \mathrm{Sb}_{0.5}$ also retains $91 \%$ of its maximum capacity after 200 cycles. The cycling stability of the materials is somewhat dependent on the substrate, where complementary data are presented in the Supplementary Information as Figure S6. Regardless of the substrate material, $\mathrm{x}=0.25$ performs best, and $\mathrm{x}=0.75$ performs worst in terms of maximum reversible capacity and stability.

Table 1. Compositions in at.\% and wt.\% and corresponding maximum measured capacity and capacity retention with respect to the maximum for the co-sputtered films. ": Sb was cycled for only 100 cycles. ${ }^{+}:$Part of the electrode had dried out, which is the likely reason for the sudden drop in capacity after cycle 175; see Figure S4.

\begin{tabular}{llll} 
Sample & Composition (wt.\% Si/100) & Max. Capacity $(\mathrm{mAh} / \mathrm{g})$ & $\mathrm{C}_{200} / \mathrm{C}_{\max }(\%)$ \\
\hline $\mathrm{Sb}$ & 0 & 625 & $75^{*}$ \\
$\mathrm{Si}_{0.07} \mathrm{Sb}_{0.93}$ & 0.017 & 663 & 100 \\
$\mathrm{Si}_{0.25} \mathrm{Sb}_{0.75}$ & 0.071 & 680 & $66^{+}$ \\
$\mathrm{Si}_{0.50} \mathrm{Sb}_{0.50}$ & 0.187 & 671 & 91 \\
$\mathrm{Si}_{0.60} \mathrm{Sb}_{0.40}$ & 0.257 & 666 & 78 \\
$\mathrm{Si}_{0.75} \mathrm{Sb}_{0.25}$ & 0.409 & 627 & 85
\end{tabular}

Increasing the Si content beyond 75 at.\% leads to a sudden drop in the capacity, as shown in Figure S7. In accordance with previous studies, pure Si has a maximum capacity of only $\sim 200 \mathrm{mAh} / \mathrm{g}$. In the aforementioned study by Chou et al., the activation barrier for Na diffusion in crystalline $\mathrm{Si}$ was found to be $1.08 \mathrm{eV}$ or $\sim 100 \mathrm{~kJ} / \mathrm{mol}$ which is nearly twice as high as that for Li diffusion $(0.62 \mathrm{eV}) .{ }^{6}$ No data for amorphous Si exist, but according to a study by Tritsaris et al., the long-range diffusion rate of $\mathrm{Li}$ is comparable in c-Si and a-Si, and thus the same may be true for $\mathrm{Na}^{20}{ }^{20}$ The low measured capacity for pure Si could therefore be due to slow rates of Na diffusion. Addition of a 
small amount of $\mathrm{Sb}$ increases the capacity to $275 \mathrm{mAh} / \mathrm{g}$ for $\mathrm{Si}_{0.92} \mathrm{Sb}_{0.08}$. Where the $\mathrm{dQ} / \mathrm{dV}$ profile of elemental $\mathrm{Si}$ is broad and completely featureless, the desodiation profile of $\mathrm{Si}_{0.92} \mathrm{Sb}_{0.08}$ has two broad features centered around 0.60 and $0.76 \mathrm{~V}$, which is somewhat similar to $\mathrm{Si}_{0.75} \mathrm{Sb}_{0.25}$ albeit with a much lower reversible capacity.

The capacities of the alloy films exceed the measured, and even the theoretical, reversible capacity of elemental $\mathrm{Sb}(=660 \mathrm{mAh} / \mathrm{g})$. The specific capacity contribution of the $\mathrm{Si}, \rho_{Q}^{S i}$, can be estimated using a simple rule-of-mixtures calculation,

$$
\rho_{Q}^{S i}=\frac{\rho_{Q}^{S i S b}-\left(1-x_{w}^{S i}\right) \rho_{Q}^{S b}}{x_{w}^{S i}}
$$

where $\rho_{Q}^{S i S b}$ and $\rho_{Q}^{S b}$ are specific capacities of the SiSb and Sb and $x_{w}^{S i}$ is the weight fraction of the silicon. From this analysis, it is found that contribution from Si varies from $630 \mathrm{mAh} / \mathrm{g}$ for $\mathrm{Si}_{0.75} \mathrm{Sb}_{0.25}$ to $1395 \mathrm{mAh} / \mathrm{g}$ for $\mathrm{Si}_{0.25} \mathrm{Sb}_{0.75}$ based on the measured capacity for elemental Sb. Based on the theoretical capacity of Sb of $660 \mathrm{mAh} / \mathrm{g}$, the $\mathrm{Si}$ contributions are between 580 and $940 \mathrm{mAh} / \mathrm{g}$, in the same order. It should be kept in mind that as the $\mathrm{wt} \%$ of $\mathrm{Si}$ becomes very small, such as for $\mathrm{Si}_{0.25} \mathrm{Sb}_{0.75}$ and even more so for $\mathrm{Si}_{0.07} \mathrm{Sb}_{0.93}$ the calculated contributions for $\mathrm{Si}$ are subject to higher uncertainties.

SEM micrographs of the films with $\mathrm{x}=0.5$ and $\mathrm{x}=0.75$ after 200 cycles are shown in Figure S5. The films show the typical 'mud-cracked' pattern of cycled, highcapacity thin film electrodes. Although some of the apparent damage could be due to the cleaning and drying steps, fracture and delamination may explain part of the observed capacity degradation for all compositions. 

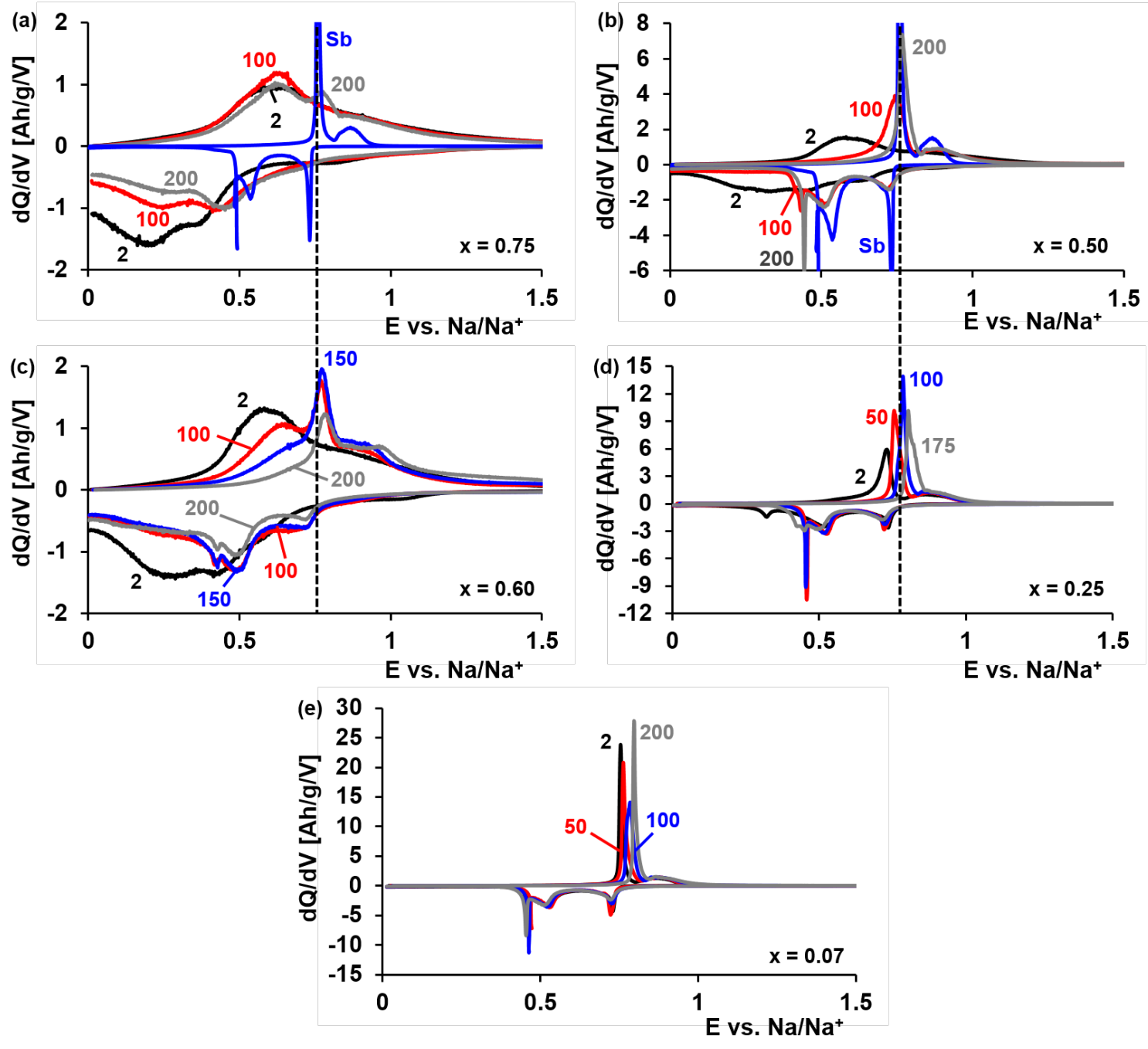

Figure 3. dQ/dV curves for selected cycles of (a) $\mathrm{Si}_{0.75} \mathrm{Sb}_{0.25}$, (b) $\mathrm{Si}_{0.60} \mathrm{Sb}_{0.40}$, (c) $\mathrm{Si}_{0.50} \mathrm{Sb}_{0.50}$ (d) $\mathrm{Si}_{0.25} \mathrm{Sb}_{0.75}$ and (e) $\mathrm{Si}_{0.07} \mathrm{Sb}_{0.93}$ co-sputtered films. The curve for elemental $\mathrm{Sb}$ has been scaled for clarity in some of the plots. Note the ever increasing range of the $\mathrm{y}$-axis with decreasing Si content as the peaks become sharper, and thus also higher.

A more detailed examination of the $\mathrm{dQ} / \mathrm{dV}$ curves in later cycles, shown in Figure 3, reveals more about the phases that form during cycling. For comparison, the second cycle is included for each composition again, as well as cycle 2 of elemental $\mathrm{Sb}$ in some of the plots. For $\mathrm{x}=0.75$, the $\mathrm{dQ} / \mathrm{dV}$ curves consist of a single broad hump and a shoulder at higher potentials, spanning almost the entire voltage range. Past 100 cycles, a small peak appears that coincides with elemental $\mathrm{Sb}$ in terms of potential in the desodiation branch. For $\mathrm{x}=0.6$, the sodiation branch develops a three-peak structure that 
is more similar to elemental $\mathrm{Sb}$, and the desodiation peak at $\sim 0.76 \mathrm{~V}$ is considerably larger than for $\mathrm{x}=0.75$. The trend continues with $\mathrm{x}=0.5$, where the sodiation profile is very similar to elemental $\mathrm{Sb}$ where the peaks are either broader $(\sim 0.73 \mathrm{~V}$ during desodiation) or shifted to lower potentials but very similar in shape ( $\sim .54$ vs. 0.51 and $\sim 0.49$ vs. $0.44 \mathrm{~V}$, respectively during sodiation). The broad peak centered around $0.55 \mathrm{~V}$ in desodiation has almost disappeared after 100 cycles, while the much sharper peak at $\sim 0.76 \mathrm{~V}$ grows simultaneously. The observed evolution of the (de)sodiation profile to resemble that of elemental $\mathrm{Sb}$ indicates that the $\mathrm{Sb}$ domains gradually grow in size upon repeated cycling and eventually become large enough to form c-Na $\mathrm{Sb}_{3} \mathrm{Sb}$.

For $\mathrm{x}=0.25$, there is a relatively sharp peak at a slightly lower desodiation potential $(\sim 0.72 \mathrm{~V})$ than elemental $\mathrm{Sb}$ right from the beginning. Over time, its position gradually shifts to higher potentials, eventually past that of elemental $\mathrm{Sb}$. The peak also becomes higher and sharper with increasing cycle number in the same manner as the materials with higher Si content, continuing the observed trend. For $\mathrm{x}=0.07$, the peaks are even sharper, and higher compared to $\mathrm{x}=0.25$ in the early cycles, although a temporary broadening of the desodiation peak is observed around cycle 100 . 


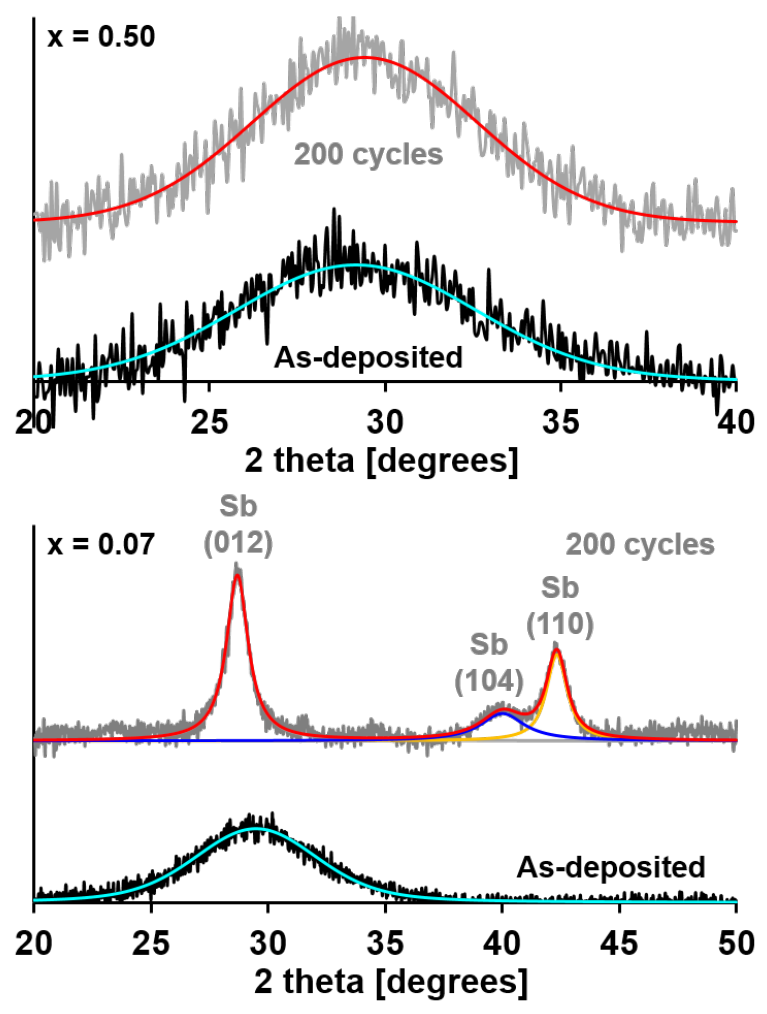

Figure 4. XRD patterns of $\mathrm{Si}_{0.5} \mathrm{Sb}_{0.5}$ and $\mathrm{Si}_{0.07} \mathrm{Sb}_{0.93}$ for as-deposited and cycled film in fully desodiated state.

Due to the high reactivity of sodiated material with air and moisture, it is very difficult to obtain diffraction patterns. On the other hand, if the sodiated state is phasesegregated into $\mathrm{Na}_{3} \mathrm{Sb}$ and $\mathrm{Na}_{\mathrm{x}} \mathrm{Si}$, as the $\mathrm{dQ} / \mathrm{dV}$ curves in Figure 3 clearly suggest, the desodiated state after a large number of cycles may be expected to show phase segregation as well. Figure 4 shows the XRD patterns for $\mathrm{x}=0.50$ and $\mathrm{x}=0.07$ in their as-deposited and cycled states. Apart from a slight decrease in the width of the peak and an increase in the signal-to-noise ratio, the cycled $\mathrm{Si}_{0.50} \mathrm{Sb}_{0.50}$ film still appears nanocrystalline after cycling, as it does in its as-deposited state. The film does crystallize during cycling when the Si content is only 7 at\%. After 200 cycles, the Sb (012), (104) and (110) peaks are clearly visible in the diffraction pattern. The intermediate $\mathrm{x}=0.25$ composition behaves identically to $\mathrm{x}=0.50$ (see Figure $\mathrm{S} 8$ ). 
The XRD result for $\mathrm{x}=0.50$ seems completely contrary to expectations based on the $\mathrm{Si}-\mathrm{Sb}$ phase diagram as well as the $\mathrm{dQ} / \mathrm{dV}$ curves that both indicate phase separation. However, intermixing and reversible segregation (crystallization)-remixing have been observed before between $\mathrm{Si}$ and $\mathrm{Sb}$. Gong et al. performed an in-situ transmission electron microscopy (TEM) study on heating of Si/Sb bilayers. Upon heating to $>775 \mathrm{~K}$ at a rate of $4 \mathrm{~K} / \mathrm{min}$ a thin $\mathrm{Sb}$ film on top of $50 \mathrm{~nm}$ or more of a-Si produced an amorphous $\mathrm{SiSb}$ solid solution as evidenced by the disappearance of $\mathrm{Sb}$ diffraction spots. Heating a bilayer with a-Si $<50 \mathrm{~nm}$ led to a mixture of c-Si and a-Sb. ${ }^{21}$ Non-equilibrium silicide formation at Si-metal interfaces has in fact been shown to be a much wider phenomenon extending to $\mathrm{Si}-\mathrm{Al}, \mathrm{Si}-\mathrm{Au}$ as well as $\mathrm{Si}-\mathrm{Sb}$, that depends strongly on layer thicknesses and heating rates. ${ }^{22-24}$ Furthermore, the transformation between a crystalline (segregated) and amorphous (mixed) state has been shown to be reversible for $\mathrm{Si}-\mathrm{Sb}$ in investigations of its application as a phase-change memory material. ${ }^{18,25,26} \mathrm{~A}$ similar phenomenon may be happening here. In a highly dispersed mixture of Si and $\mathrm{Sb}$ in the fully desodiated state, the interfacial energy of the system as a whole may be lowered by forming a homogeneous amorphous phase. This would also explain why the Sb-rich composition at $\mathrm{x}=0.07$ does crystallize as there is simply not enough $\mathrm{Si}$ to form a single amorphous phase.

On the other hand, the appearance of ever sharper and larger features characteristic of $\mathrm{c}-\mathrm{Na}_{3} \mathrm{Sb}$ in the $\mathrm{dQ} / \mathrm{dV}$ curves do suggest that $\mathrm{Sb}$ or $\mathrm{Sb}$-rich domains grow in the course of cycling. This suggests that although the cycled, desodiated material presents as fully X-ray amorphous, the material may be phase segregated to some extent after all, where both $\mathrm{Si}$ and $\mathrm{Sb}$ are amorphous. When the film is 'pre'-segregated at $2 \mathrm{~nm}$ 
length scale by depositing it as a multilayer, the as-deposited state is also X-ray amorphous as shown in Figure S8, although interdiffusion between layers, especially during deposition when the film is being bombarded with argon ions, cannot be ruled out. In-situ studies with techniques that directly probe nearest neighbor environments such as pair-distribution-function analysis, ${ }^{27}$ or Mossbauer spectroscopy, ${ }^{28}$ will be needed to shed more light on the exact reaction mechanisms here.

Table 2. Capacities in the first cycle and maximum capacities of $\mathrm{Si} / \mathrm{Sb}$ multilayers compared to co-sputtered $\mathrm{Si}_{0.60} \mathrm{Sb}_{0.40}\left({ }^{6}{ }^{6}{ }^{\prime}\right.$ ' bilayer thickness)

\begin{tabular}{lll} 
Bilayer thickness $(\mathrm{nm})$ & Cycle 1 capacity $(\mathrm{mAh} / \mathrm{g})$ & Maximum Capacity $(\mathrm{mAh} / \mathrm{g})$ \\
\hline 0 & 665 & 666 \\
2 & 619 & 638 \\
4 & 592 & 624 \\
20 & 520 & 560
\end{tabular}

To further investigate the relationship between phase-segregation and the voltage profile as well as maximum capacity, multilayers of $\mathrm{Si}$ and $\mathrm{Sb}$ were also investigated. The multilayers consisted of alternating layers of $\mathrm{Si}$ and $\mathrm{Sb}$, where the total thickness was kept constant at $100 \mathrm{~nm}$ and the overall composition was fixed at $\mathrm{Si}_{0.60} \mathrm{Sb}_{0.40}$ (equivalent to a total $50 \mathrm{~nm}$ of $\mathrm{Si}$ and $50 \mathrm{~nm}$ of $\mathrm{Sb}$ ). Three different bilayer thicknesses, $\operatorname{Si}(10 \mathrm{~nm}) / \mathrm{Sb}(10 \mathrm{~nm})$ with 5 repetitions, $\operatorname{Si}(2 \mathrm{~nm}) / \mathrm{Sb}(2 \mathrm{~nm})$ with 25 repetitions and $\mathrm{Si}(1 \mathrm{~nm}) / \mathrm{Sb}(1 \mathrm{~nm})$ with 50 repetitions were sputtered onto stainless steel substrates and cycled under identical conditions as the co-sputtered films. The films are designated as 10/10,2/2 and 1/1 or by their bilayer thickness of 20,4 and $2 \mathrm{~nm}$, from here on.

The initial capacity decreases in the order $\mathrm{Si}_{0.60} \mathrm{Sb}_{0.40}$ (co-sputtered) $>1 / 1>2 / 2$ $>10 / 10$ multilayers and the same is true for the maximum capacities as summarized in 
Table 2. The Si-specific contributions (cycle 1) amount to 675,497 and $216 \mathrm{mAh} / \mathrm{g} \mathrm{Si}$ based on the measured capacity of $100 \mathrm{~nm} \mathrm{Sb}$ using the rule-of-mixtures calculation outlined previously. The decreasing trend with increasing layer thickness is in agreement with the low measured capacity for elemental $\mathrm{Si}$ as well as the decrease in capacity with increasing Si content observed for the co-sputtered films.
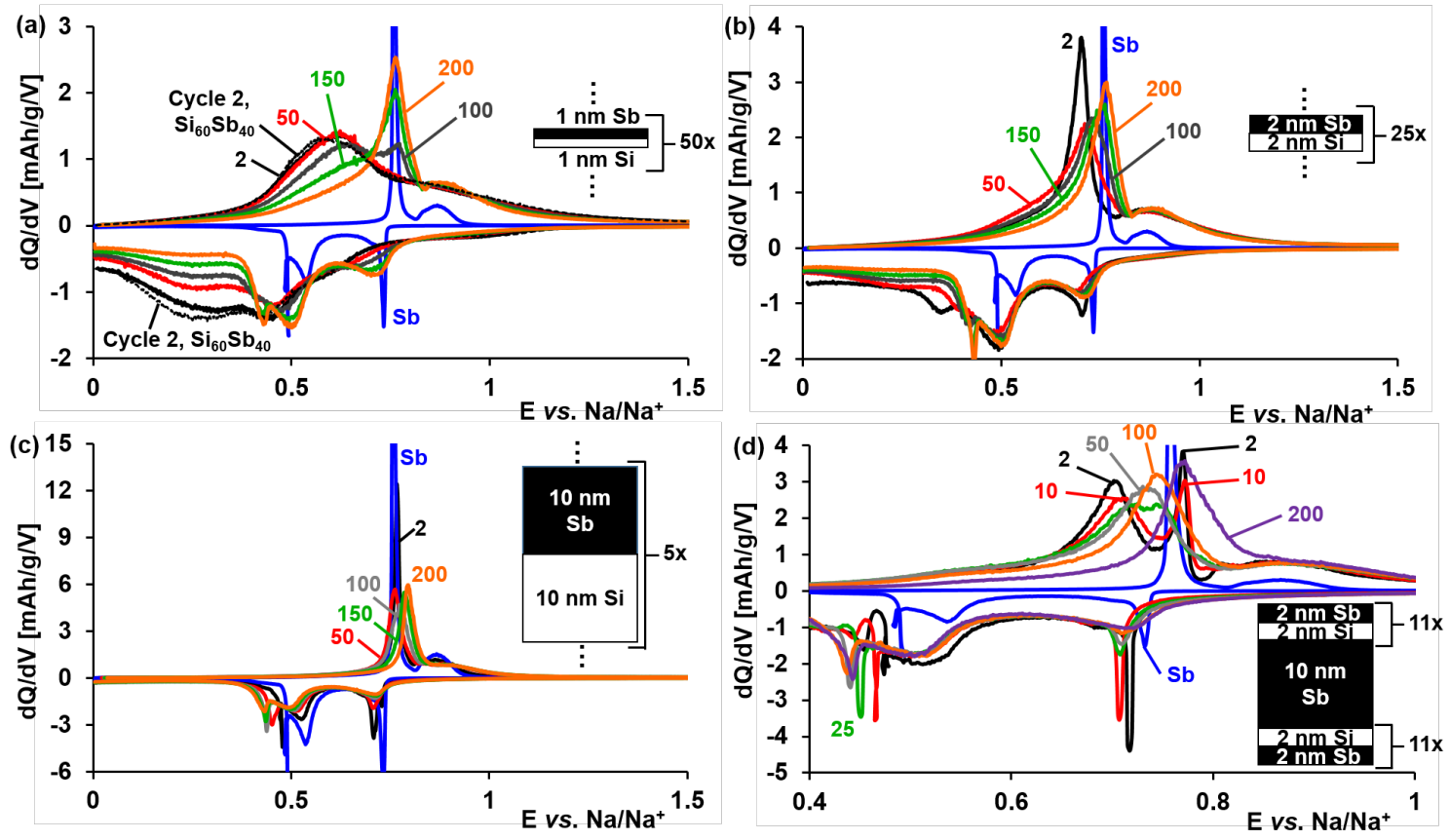

Figure 5. dQ/dV curves of selected cycles for $1 / 1$ (a), 2/2 (b) and 10/10 (c) Si/Sb multilayers. Total thickness was always $100 \mathrm{~nm}$, same as for co-sputtered films. dQ/dV plots for a $2 / 2$ multilayer with a central $10 \mathrm{~nm} \mathrm{Sb}$ layer are shown in (d). Note that the numbers in the plot connected to individual curves refer to cycle numbers.

Figure 5 shows the dQ/dV curves for selected cycles of the multilayers. The corresponding voltage profiles are shown in Figure S9. From comparing Figure 3 and Figure 5 it is obvious that the $1 / 1$ multilayer and the co-sputtered films show very similar behavior. The initial desodiation $\mathrm{dQ} / \mathrm{dV}$ profile consisting of two broad humps gradually evolves towards one where a much sharper peak at a potential very close to that of 
elemental $\mathrm{Sb}$ is visible. The sodiation profiles also look nearly identical both in the $2 \mathrm{nd}$ and 200th cycle (compare with Figure 3c).

For the $2 / 2$ multilayer, the picture is quite different. There is a large, relatively sharp peak in the desodiation branch at $\sim 0.70 \mathrm{~V}$, shifted by $\sim 60 \mathrm{mV}$ from the peak position for elemental $\mathrm{Sb}$, already in the second cycle. The height of this peak first decreases gradually and shifts towards higher potentials until, at cycle 200 , its position coincides with that of elemental $\mathrm{Sb}$ and the 1/1 multilayer. The sodiation branch goes through a similar evolution. The second cycle clearly shows three very broad peaks one of which nearly disappears by the 50th cycle while also shifting from $\sim 0.35$ to $0.4 \mathrm{~V}$. By the 200th cycle, the sodiation branches of the $1 / 1$ and $2 / 2$ multilayer films are very similar, same as the desodiation.

Although the capacity is considerably lower initially for the $10 / 10$ multilayer compared to $2 / 2$, the shape and evolution of the $\mathrm{dQ} / \mathrm{dV}$ profiles are very similar. There is a large, sharp peak around $0.76 \mathrm{~V}$ in the desodiation branch that rapidly decreases in height with cycling. The sodiation profile on the other hand, is very close to that of elemental $\mathrm{Sb}$ although the peak at $\sim 0.7 \mathrm{~V}$ broadens considerably with cycling. The desodiation peak around $0.76 \mathrm{~V}$ continues to broaden up to cycle 100 before sharpening again between cycles 100 and 200, as it does in the $2 / 2$ multilayer.

It should be noted that the height of the peaks increases with increasing layer thickness, as is obvious from the increasing range of the y-axis going from Figure 5a-c. Together with the decrease in the capacity, this clearly indicates that with increasing layer thickness, it is mainly the $\mathrm{Sb}$ that is active towards sodiation, while the contribution from 
Si diminishes, and that increasing the thickness of the Sb layers makes them behave more similarly to bulk $\mathrm{Sb}$.

The broadening of the peaks in the $\mathrm{dQ} / \mathrm{dV}$ profiles of the $2 / 2$ and $10 / 10$ multilayers between cycles 2 and 50 shows that there is, initially, a driving force for intermixing between the layers. The final state of the $2 / 2$ multilayer film in particular is very similar to that of the co-sputtered film, as evidenced by the close similarities of their $\mathrm{dQ} / \mathrm{dV}$ curves. A multilayer stack has a very high interfacial-area-to-volume ratio, which will be lowered by mixing between the Sb and Si layers. Beyond the 100th cycle, the $\mathrm{dQ} / \mathrm{dV}$ peaks for the multilayer films sharpen again, similar to the co-sputtered films. This shows that the initial 'mixing' trend is eventually reversed to increasing segregation into Sb-rich and Si-rich domains at high Na concentrations, the same as in the cosputtered films.

In order to test this 'mixing-followed-by-demixing' hypothesis further, a multilayer with $10 \mathrm{~nm} \mathrm{Sb}$ in the middle and 11 bilayers of $2 \mathrm{~nm} \mathrm{Si}$ and $2 \mathrm{~nm} \mathrm{Sb}$ below and above was cycled 200 times as well. In this case, there are two distinct peaks in the $\mathrm{dQ} / \mathrm{dV}$ curve as shown in Figure $5 \mathrm{~d}$ at potentials separated by $\sim 65 \mathrm{mV}$. The peak at lower potential, $\sim 0.70 \mathrm{~V}$, is due to the $2 \mathrm{~nm}$ layers, and the other at $\sim 0.76 \mathrm{~V}$ to the $10 \mathrm{~nm} \mathrm{Sb}$ layer. Over the course of cycling, the peak potentials shift closer to each other while the peaks simultaneously broaden as well. After 50 cycles, the peaks have merged and further evolution of voltage profile once again resembles that of co-sputtered $\mathrm{Si}_{0.60} \mathrm{Sb}_{0.40}$ and the $1 / 1$ and $2 / 2$ multilayers. If mixing did not occur in the initial stages of cycling, the peak related to the $10 \mathrm{~nm}$ Sb layer would have remained unchanged. 


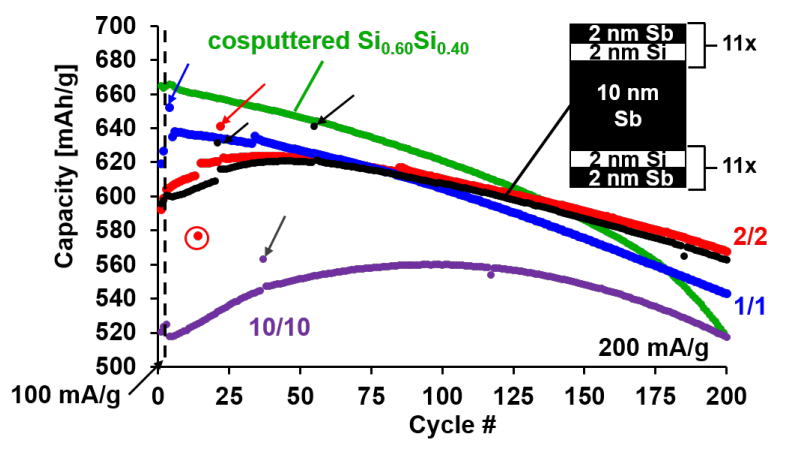

Figure 6. Capacity vs. cycle number of $\mathrm{Si} / \mathrm{Sb}$ multilayers. Individual layer thicknesses are indicated in the plot. Co-sputtered $\mathrm{Si0.60Sb0.40} \mathrm{is} \mathrm{included} \mathrm{for} \mathrm{comparison.} \mathrm{The}$ arrows indicate cycles where a second sodiation step at $20 \mathrm{~mA} / \mathrm{g}$ was included. The circled point is where desodiation was performed at $20 \mathrm{~mA} / \mathrm{g}$ instead of $200 \mathrm{~mA} / \mathrm{g}$. The apparently lower capacity is probably due to direct (electro-less) reaction of the sodiated material with the electrolyte occurring at the same time. ${ }^{29}$

The capacity as a function of cycle number for the multilayers in Figure 5 is shown in Figure 6. Co-sputtered $\mathrm{Si}_{0.60} \mathrm{Sb}_{0.40}$ is also included for comparison. The cycles where the reversible capacity of the multilayers increases are also the ones where their $\mathrm{dQ} / \mathrm{dV}$ curves evolve to more closely resemble the initial cycles of co-sputtered $\mathrm{Si}_{0.60} \mathrm{Sb}_{0.40}$. The maximum capacity at $200 \mathrm{~mA} / \mathrm{g}$ is reached in the fifth cycle for the $1 / 1$ multilayer. The cycle number where the maximum capacity is reached increases with increasing Si layer thickness and increases to cycle 39 for the $2 / 2$ multilayer and cycle 80 for the 10/10. This further strengthens the argument that $\mathrm{Si}$ and $\mathrm{Sb}$ mix initially and that improved mixing between $\mathrm{Si}$ and $\mathrm{Sb}$ increases the reversible capacity.

The points indicated by arrows in Figure 6 denote cycles where the sodiation step at $200 \mathrm{~mA} / \mathrm{g}$ was followed by a second one at $20 \mathrm{~mA} / \mathrm{g}$ after the lower cut-off potential had been reached. The desodiation capacity is significantly higher than the preceding cycle in each case and reaches a maximum of 652,641 and $563 \mathrm{mAh} / \mathrm{g}$ for the $1 / 1,2 / 2$ and 10/10 multilayers, respectively. The difference in the capacity between sodiating at $200 \mathrm{~mA} / \mathrm{g}$ and using a second, low current step, does not appear to depend on 
the bilayer thickness or the cycle number. Upon reverting to a single sodiation step at 200 $\mathrm{mA} / \mathrm{g}$, the reversible capacity returns to its previous value or the preceding trend, showing that the desodiated state is not influenced by driving the material to a higher $\mathrm{Na}$ concentration for a longer time. This strongly suggests that homogenization of the $\mathrm{Si}$ and $\mathrm{Sb}$ concentration does not occur at high $\mathrm{Na}$ concentration but rather at low $\mathrm{Na}$ content or even close to the fully desodiated state, as discussed previously.

The fact that even initially phase-separated $\mathrm{Si}-\mathrm{Sb}$ mixtures show a tendency to mix initially is important for two reasons. First, it is in the fully mixed (alloyed) state that both elements make their highest contribution to the total reversible capacity. Second, it opens up some interesting possibilities for transferring our results on thin films to bulk materials. If it is not necessary to start from a single-phase material, then a physical mixture of Si and Sb nanoparticles might work equally well. Ball-milling commercially available powders or solvothermal routes with a mixture of precursors, as was demonstrated for $\mathrm{SnSb}^{30}$ are worth considering. More generally, other materials that are being investigated for phase-change memory applications, as $\mathrm{Si}-\mathrm{Sb}$ has been, may be suitable for SIB or LIB applications as well. The Ge-Sb-Te (GST) ternary system has been thoroughly investigated for $\mathrm{PCM}^{31,32}$ and all three constituents form compounds with $\mathrm{Na} .{ }^{14}$ Whereas $\mathrm{Al}$ is not reactive with $\mathrm{Na}$, although it is with Li, the AlSb binary compound has been found to perform well as both a SIB and LIB anode. ${ }^{33}$ Furthermore, it showed promise as a PCM material over a wider compositional range. ${ }^{34}$ In order to further improve the cycling stability of $\mathrm{Sb}$ or $\mathrm{Si}-\mathrm{Sb}$, a low amount of $\mathrm{Al}$, less than 1:1 ratio with Sb, may be sufficient. 


\section{CONCLUSIONS}

Co-deposited $\mathrm{Si}-\mathrm{Sb}$ alloys show reversible capacity exceeding that of elemental $\mathrm{Sb}$. The cycling stability when tested as thin films in half-cells is superior to elemental Sb as well, which could translate to standard powder electrode configurations in full cells. The optimum composition lies at the $\mathrm{Sb}$-rich end of the compositional range. $\mathrm{Si}_{0.07} \mathrm{Sb}_{0.93}$ and $\mathrm{Si}_{0.25} \mathrm{Sb}_{0.75}$ reach a maximum capacity of more than $660 \mathrm{mAh} / \mathrm{g}$ (maximum capacity of pure $\mathrm{Sb}$ ) after more than 100 cycles and show only minimal degradation after that. Elemental Si shows poor reactivity with $\mathrm{Na}$. As a consequence, the reversible capacity of the co-deposited materials decreases with increasing Si content, contrary to the expected trend based on formation of $\mathrm{NaSi}$. The fully sodiated state is a mixture of $\mathrm{Na}_{3} \mathrm{Sb}$ and $\mathrm{Na}_{\mathrm{x}} \mathrm{Si}$ and the dQ/dV curves of the co-sputtered films show clear signs of grain growth of $\mathrm{Na}_{3} \mathrm{Sb}$ with cycling. However, despite phase segregating and crystallizing upon sodiation, it appears that after desodiation the films re-mix into a single amorphous phase.

Multilayer films show a very interesting and analogous evolution with cycling.

First, their $\mathrm{dQ} / \mathrm{dV}$ curves start to resemble those of the first cycles of co-sputtered material more and more, indicating intermixing between the $\mathrm{Si}$ and $\mathrm{Sb}$ layers. After reaching a maximum capacity, they continue to follow the same path as co-sputtered material with the (re-)emergence of a sharp peak at $\sim 0.76 \mathrm{~V}$ related to $\mathrm{Na}_{3} \mathrm{Sb}$. The capacity and cycling stability of the multilayers is comparable to co-sputtered material with the same volume fractions of $\mathrm{Si}$ and $\mathrm{Sb}$. This significantly enhances the prospects of synthesizing bulk analogues of these materials for use in powder electrodes. Besides Si$\mathrm{Sb}$, other promising binary and ternary combinations may be found among phase-change memory materials such as Ge-Sb-Te or Sb-Al. 


\section{Associated Content}

\section{Supporting Information}

XRD patterns of as-deposited and annealed films, Coulombic Efficiency of $\operatorname{Si}_{\mathrm{x}} \mathrm{Sb}_{1-\mathrm{x}}(\mathrm{x}=$ 0.07-0.75), SEM micrographs of cycled electrodes, additional electrochemical cycling data on $\mathrm{Si}_{\mathrm{x}} \mathrm{Sb}_{1-\mathrm{x}}(\mathrm{x}=0.07-0.92)$ as well as pure $\mathrm{Si}, \mathrm{XRD}$ patterns of cycled electrodes, comparison of the voltage profiles of multilayer films at selected cycles and detailed deposition conditions for all electrodes.

\section{Author Information}

\section{Corresponding Authors}

*E-mail: (W.P.K) pkalisva@ualberta.ca

*E-mail: (J.M.B) jburiak@ualberta.ca

\section{ORCID}

W. Peter Kalisvaart: 0000-0003-1228-906X

Erik J. Luber: 0000-0003-1623-0102

Brian C. Olsen: 0000-0001-9758-3641

Jillian M. Buriak: 0000-0002-9567-4328

\section{Notes}

The authors declare no competing financial interest.

\section{ACKNOWLEDGMENTS}

This work was supported by Western Economic Diversification (WD), Future Energy

Systems of the University of Alberta (https://futureenergysystems.ca; grant number T12P04), the Natural Sciences and Engineering Research Council (NSERC, grant number RGPIN-2014-05195), Alberta Innovates Technology Futures (grant number AITF iCORE IC50-T1 G2013000198), and the Canada Research Chairs program (CRC 207142) 


\section{REFERENCES}

(1) Jin, Y.; Zhu, B.; Lu, Z.; Liu, N.; Zhu, J. Challenges and Recent Progress in the Development of Si Anodes for Lithium-Ion Battery. Adv. Energy Mater. 2017, 7 (23), 1700715.

(2) Aghajamali, M.; Xie, H.; Javadi, M.; Kalisvaart, W. P.; Buriak, J. M.; Veinot, J. G. C. Size and Surface Effects of Silicon Nanocrystals in Graphene Aerogel Composite Anodes for Lithium Ion Batteries. Chem. Mater. 2018, 30 (21), 7782-7792.

(3) Xu, Y.; Swaans, E.; Basak, S.; Zandbergen, H. W.; Borsa, D. M.; Mulder, F. M. Reversible Na-Ion Uptake in Si Nanoparticles. Adv. Energy Mater. 2016, 6 (2), 1501436.

(4) Jangid, M. K.; Vemulapally, A.; Sonia, F. J.; Aslam, M.; Mukhopadhyay, A.

Feasibility of Reversible Electrochemical Na-Storage and Cyclic Stability of Amorphous Silicon and Silicon-Graphene Film Electrodes. J. Electrochem. Soc. 2017, 164 (12), A2559-A2565.

(5) Qiu, D.-F.; Ma, X.; Zhang, J.-D.; Lin, Z.-X.; Zhao, B. Mesoporous Silicon Microspheres Produced from in Situ Magnesiothermic Reduction of Silicon Oxide for High-Performance Anode Material in Sodium-Ion Batteries. Nanoscale Res Lett 2018, 13 (1), 275.

(6) Chou, C.-Y.; Lee, M.; Hwang, G. A Comparative First-Principles Study on Sodiation of Silicon, Germanium, and Tin for Sodium-Ion Batteries. J. Phys. Chem. C 2015, 119 (27), 14843-14850.

(7) Xie, H.; Peter Kalisvaart, W.; C. Olsen, B.; J. Luber, E.; Mitlin, D.; M. Buriak, J. Sn$\mathrm{Bi}-\mathrm{Sb}$ Alloys as Anode Materials for Sodium Ion Batteries. J. Mater. Chem. A 2017, 5 (20), 9661-9670.

(8) Gabaudan, V.; Berthelot, R.; Stievano, L.; Monconduit, L. Inside the Alloy Mechanism of Sb and Bi Electrodes for K-Ion Batteries. J. Phys. Chem. C 2018, 122 (32), 18266-18273. 
(9) Darwiche, A.; Marino, C.; Sougrati, M. T.; Fraisse, B.; Stievano, L.; Monconduit, L. Better Cycling Performances of Bulk Sb in Na-Ion Batteries Compared to Li-Ion Systems: An Unexpected Electrochemical Mechanism. J. Am. Chem. Soc. 2012, 134 (51), 20805-20811.

(10) Qian, J.; Chen, Y.; Wu, L.; Cao, Y.; Ai, X.; Yang, H. High Capacity Na-Storage and Superior Cyclability of Nanocomposite Sb/C Anode for Na-Ion Batteries. Chem. Commun. 2012, 48 (56), 7070-7072.

(11) He, M.; Kravchyk, K.; Walter, M.; Kovalenko, M. V. Monodisperse Antimony Nanocrystals for High-Rate Li-Ion and Na-Ion Battery Anodes: Nano Versus Bulk. Nano Lett. 2014, 14 (3), 1255-1262.

(12) Liang, L.; Xu, Y.; Li, Y.; Dong, H.; Zhou, M.; Zhao, H.; Kaiser, U.; Lei, Y. Facile Synthesis of Hierarchical Fern Leaf-Like Sb and Its Application as an Additive-Free Anode for Fast Reversible Na-Ion Storage. J. Mater. Chem. A 2017, 5 (4), 1749-1755.

(13) Selvaraj, B.; Huang, S.-S.; Wu, C.-E.; Lin, Y.-H.; Wang, C.-C.; Song, Y.-F.; Lu, M.L.; Sheu, H.-S.; Wu, N.-L. Micrometer-Sized Nanoporous Sb/C Anode with High Volumetric Capacity and Fast Charging Performance for Sodium-Ion Batteries. ACS Appl. Energy Mater. 2018, 1 (5), 2317-2325.

(14) Okamoto, H. Desk Handbook: Phase Diagrams for Binary Alloys; ASM International, 2000.

(15) Farbod, B.; Cui, K.; Kalisvaart, W. P.; Kupsta, M.; Zahiri, B.; Kohandehghan, A.; Lotfabad, E. M.; Li, Z.; Luber, E. J.; Mitlin, D. Anodes for Sodium Ion Batteries Based on Tin-Germanium-Antimony Alloys. ACS Nano 2014, 8 (5), 4415-4429.

(16) Kohandehghan, A.; Cui, K.; Kupsta, M.; Ding, J.; Memarzadeh Lotfabad, E.; Kalisvaart, W. P.; Mitlin, D. Activation with Li Enables Facile Sodium Storage in Germanium. Nano Lett. 2014, 14 (10), 5873-5882. 
(17) Carlsson, J. R. A.; Sundgren, J. E.; Madsen, L. D.; Li, X. H.; Hentzell, H. T. G. Thermal Stability and Crystallization of Amorphous $\mathrm{Si}_{1_{-x}} \mathrm{~B}_{\mathrm{x}}, \mathrm{Si}_{1_{-x}} \mathrm{P}_{\mathrm{x}}$ and $\mathrm{Si}_{1_{-x}} \mathrm{Sb}_{\mathrm{x}}$ Alloy Thin Films. Thin Solid Films 1997, 300 (1), 51-58.

(18) Zhang, T.; Song, Z.; Liu, B.; Feng, S. Investigation of Environmental Friendly TeFree SiSb Material for Applications of Phase-Change Memory. Semicond. Sci. Technol. 2008, $23(5), 055010$.

(19) Obrovac, M. N.; Chevrier, V. L. Alloy Negative Electrodes for Li-Ion Batteries. Chem. Rev. 2014, 114 (23), 11444-11502.

(20) Tritsaris, G. A.; Zhao, K.; Okeke, O. U.; Kaxiras, E. Diffusion of Lithium in Bulk Amorphous Silicon: A Theoretical Study. J. Phys. Chem. C 2012, 116 (42), 2221222216.

(21) Gong, S. F.; Hentzell, H. T. G.; Robertsson, A. E. Initial Solid state Reactions Between Crystalline Sb and Amorphous Si Thin Films. Journal of Applied Physics 1988, $64(3), 1457-1463$.

(22) Hultman, L.; Robertsson, A.; Hentzell, H. T. G.; Engström, I.; Psaras, P. A. Crystallization of Amorphous Silicon During Thin film Gold Reaction. Journal of Applied Physics 1987, 62 (9), 3647-3655.

(23) Hiraki, A. Initial Formation Process of Metal/Silicon Interfaces. Surface Science 1986, $168(1), 74-99$.

(24) Herd, S. R.; Ahn, K. Y.; Tu, K. N. Formation and Crystallization of Amorphous Silicides at the Interface Between Thin Metal and Amorphous Silicon Films. Thin Solid Films 1983, 104 (1), 197-206.

(25) Zhang, T.; Song, Z.; Wang, F.; Liu, B.; Feng, S.; Chen, B. Advantages of SiSb Phase-Change Material and Its Applications in Phase-Change Memory. Appl. Phys. Lett. 2007, 91 (22), 222102. 
(26) Zhang, T.; Song, Z.; Wang, F.; Liu, B.; Feng, S.; Chen, B. Te-Free SiSb Phase Change Material for High Data Retention Phase Change Memory Application. Jpn. J. Appl. Phys. 2007, 46 (7L), L602.

(27) Talaie, E.; Bonnick, P.; Sun, X.; Pang, Q.; Liang, X.; Nazar, L. F. Methods and Protocols for Electrochemical Energy Storage Materials Research. Chem. Mater. 2017, $29(1), 90-105$.

(28) Baggetto, L.; Hah, H.-Y.; Jumas, J.-C.; Johnson, C. E.; Johnson, J. A.; Keum, J. K.; Bridges, C. A.; Veith, G. M. The Reaction Mechanism of SnSb and Sb Thin Film Anodes for Na-Ion Batteries Studied by X-Ray Diffraction, 119Sn and 121Sb Mössbauer Spectroscopies. Journal of Power Sources 2014, 267, 329-336.

(29) Mogensen, R.; Brandell, D.; Younesi, R. Solubility of the Solid Electrolyte Interphase (SEI) in Sodium Ion Batteries. ACS Energy Lett. 2016, 1 (6), 1173-1178.

(30) He, M.; Walter, M.; Kravchyk, K. V.; Erni, R.; Widmer, R.; Kovalenko, M. V. Monodisperse SnSb Nanocrystals for Li-Ion and Na-Ion Battery Anodes: Synergy and Dissonance Between Sn and Sb. Nanoscale 2015, 7 (2), 455-459.

(31) Zhou, W.; Wu, L.; Zhou, X.; Rao, F.; Song, Z.; Yao, D.; Yin, W.; Song, S.; Liu, B.; Qian, B.; et al. High Thermal Stability and Low Density Variation of Carbon-Doped Ge2Sb2Te5 for Phase-Change Memory Application. Appl. Phys. Lett. 2014, 105 (24), (32) Xue, Y.; Song, S.; Yan, S.; Guo, T.; Song, Z.; Feng, S. Al-Sb-Ge Phase Change Material: A Candidate for Multilevel Data Storage with High-Data Retention and Fast Speed. Scripta Materialia 2018, 157, 152-156.

(33) Baggetto, L.; Marszewski, M.; Górka, J.; Jaroniec, M.; Veith, G. M. AlSb Thin Films as Negative Electrodes for Li-Ion and Na-Ion Batteries. Journal of Power Sources 2013, 243, 699-705.

(34) Zhou, X.; Wu, L.; Song, Z.; Rao, F.; Ren, K.; Peng, C.; Song, S.; Liu, B.; Xu, L.; Feng, S. Phase Transition Characteristics of Al-Sb Phase Change Materials for Phase Change Memory Application. Appl. Phys. Lett. 2013, 103 (7), 072114. 